\title{
Application of BIM in Building Electrical Design
}

\author{
Chen Nan* \\ Information and Control Engineering Academy, \\ Shenyang Jianzhu University \\ Shen Yang, China \\ e-mail: arnold0110@ sina.com \\ * Corresponding Author \\ Kan Fenglong \\ Information and Control Engineering Academy, \\ Shenyang Jianzhu University \\ Shen Yang, China \\ Wang Changtao \\ Information and Control Engineering Academy, \\ Shenyang Jianzhu University \\ Shen Yang, China \\ Wang Xin \\ School of Information \& Control Engineering \\ Shenyang Jianzhu University \\ Shenyang, China
}

\author{
Qi Ning \\ Library \\ Shenyang Jianzhu University \\ Shenyang, China \\ Liu Xiyang \\ School of Information \& Control Engineering \\ Shenyang Jianzhu University \\ Shenyang, China \\ Mao Yongming \\ School of Information \& Control Engineering \\ Shenyang Jianzhu University \\ Shenyang, China \\ Wang Bin \\ Northeastern University at Qinhuangdao \\ Qinhuangdao, China
}

\begin{abstract}
Building Information Modeling (BIM) in the field of domestic construction is being more and more people are familiar with the application, In this paper, the application of BIM technology in the field of building electrical design is discussed. Objective: The application of BIM technology in building electrical design is discussed and studied. Methods: The process and characteristics of the application of BIM technology in building electrical design are discussed, and the differences between the traditional design process and BIM design flow are compared. Results : Through the flow chart, it can be seen that the application of BIM technology in the field of building electrical design, the work flow and data transfer will have obvious changes, significantly improve the design quality. Conclusion : BIM technology is still in the initial stage of exploration in the application of electrical specialty, still need to cause the wide attention and careful exploration of the electrical design workers.
\end{abstract}

Keywords-Building Information Modeling(BIM);building electrical; design; application; process

\section{INTRODUCTION}

In recent years, The building Information Modeling (BIM) is considered to be the global construction industry revolutionary ideas and the landmark technology, started to cause the extensive concern of the global industry.[1] In western countries, the number of projects has been more than the traditional application of BIM projects. Domestic BIM application relatively late start, the current number of project implementation process has also begun to be applied [2]. BIM application in the construction industry in
China has achieved initial success, especially for complex projects, but at the same time there are many problems. $\mathrm{BIM}$ integrates all the geometrical information, functional requirements, and component performance, A construction project throughout the life cycle of all information into a separate building model, Including the construction progress, construction process and maintenance management process information [3]. The American Institute of architects to further define BIM as a "combination of engineering project information database model technology".[4] BIM is considered to be a new tool in the construction industry, in the traditional architectural design and nonlinear design and other complex degree is relatively high, the difficulty of building design, BIM provides a good basis for the design of [5]. At the same time, the application of BIM technology in the architectural design of electrical professional. Application of BIM technology to break through the limits of $2 \mathrm{D}$, the electrical design, the realization of the communication between the professional designers, to ensure the design intent and construction quality are important.[6] At present, the design stage and construction stage of the domestic part of the project are in the "isolated" state in the whole life cycle of the construction project, but the operational phase is in the "isolated" state in the whole life cycle of the construction project, which is the key of the development of the future. In this paper, the application of BIM technology in building electrical design is studied. 


\section{APPLICATION OF BIM IN BUILDING ELECTRICAL}

\section{A. The concept of BIM}

BIM is a new method of building design, construction and management, based on three-dimensional digital technology, planning, design, construction and operation of the data, all included in the 3D model, so that the entire life cycle of the building in the model, can have accurate and complete data, help project designers to improve the efficiency and correctness of decision-making. BIM makes building, structure, water supply and drainage, HVAC, electrical and other professional based on the same model to work, so that the real sense of three-dimensional integration of collaborative design becomes possible. With the development of BIM technology, the application of BIM in electrical specialty has more development prospects.[7] In the software built into the localization specification, can realize the electrical design of automatic correction work, speed up the review process; application BIM model, can realize the power system, intelligent lighting system, fire system, security system and equipment monitoring system and other electrical system management, raise the level of intelligent building.

\section{B. Brief introduction to BIM software for electrical specialty}

At present, the software of electrical BIM can be classified into two categories: the first category is the full three-dimensional software, the Autodesk Revit MEP (Mechanical, Electrical \& Plumbing) software as the representative. Revit MEP is a professional software developed by Autodesk company for the design of Mechanical, Electrical \& Plumbing designers and graphics, The biggest characteristic is that it can directly design the visualization of $3 \mathrm{D}$ graphics through parametric modeling, and it is used in 3D pipeline design. [8] The advantage is that it is possible to develop into an upgrade and replace the current mainstream design software AutoCAD series of software. The disadvantage is that the current for the water and electricity professional parts (especially the electrical professional) of the module is still very immature, the requirements of the actual engineering design and the larger gap. The second category is the "two dimensional" software, such as MagiCAD, and other auxiliary software as a representative. MagiCAD and other auxiliary software AutoCAD as the basic platform to use the original part of the CAD to increase the corresponding parameters of the BIM function. The advantage is that the software is based on CAD platform, the operation is close to the current CAD, running smoothly, the current claims to achieve the design of equipment (plumbing) BIM mostly use this category of software. [9]The disadvantage is that the software is not a native of the three-dimensional property, many settings are one-way, although it can meet the needs of modeling, but not like MEP Revit support for two-way synchronization, drawing modification must be modified, and then update the drawings, and then to face the process. At present, the two kinds of software have advantages and disadvantages, and it is also weak in the application of electrical specialty. However, in the final analysis BIM is a platform, systematic work, we should weigh the pros and cons, comprehensive consideration to choose the appropriate software. I believe that the compatibility between the major is the focus of consideration, the best is the best in the same software platform, to make the best quality and reliable drawings. In comparison, MEP Revit is more mature and stable in compatibility.

\section{Application of BIM technology in electrical design}

At this stage, the application of BIM technology in electrical specialty mainly has the power distribution design, lighting design, fire protection design, weak current design and three-dimensional collision detection. [10]In power distribution design, electrical engineering can be used to collect the dynamic conditions of HVAC and water supply and drainage through BIM technology. BIM technology can be used to check whether the power circuit is perfect. When the dynamic conditions change, the distribution system will automatically adjust, which avoids the previous two dimensional design of the fault, the leakage power conditions, in the generation of power distribution system, the software can automatically load balance adjustment, greatly enhanced the quality of power supply. In lighting design, lighting standard design personnel can be set for each function room first in accordance with the standard value, in the layout of lamps can view real-time meet the standard design requirements, accelerate the design speed, improve the quality of the design; the fire control design, the application of BIM software to check whether the protection function, you can view the fire detector to meet the specification the software can also collect requirements, HVAC, fire linkage to professional and professional electrical drainage conditions, the more reliable, fire safety design of electrical specialty; in the 3D collision checking process, electrical professional electric and electronic bridge based on the analysis of 3D model, carries on the adjustment to the collision point, meet the requirements of construction site, these in the two-dimensional electrical design can not be achieved.[11] The advantages of BIM in the application of BIM in building electrical design are analyzed in detail.

\section{THE CHANGE OF ELECTRICAL DESIGN BASED ON BIM}

In the design of BIM, there are still some initial design stage and construction drawing design stage. In a specific design stage, the BIM model can be shared among professional and professional, so as to avoid the duplication of modeling and design information is lost.

\section{A. Traditional electrical design process}

The traditional electrical design process is based on two-dimensional patterns, as shown in Figure 1. The electrical specialty is based on the design of building professional design and design work, and the construction of professional and other professional design plan for review confirmed that the technical parameters and requirements of the professional, and then carry out electrical design based on two-dimensional drawings. In this process, the electrical professional and other professional mutual information. After the design is completed, the approval, delivery and filing of the. 


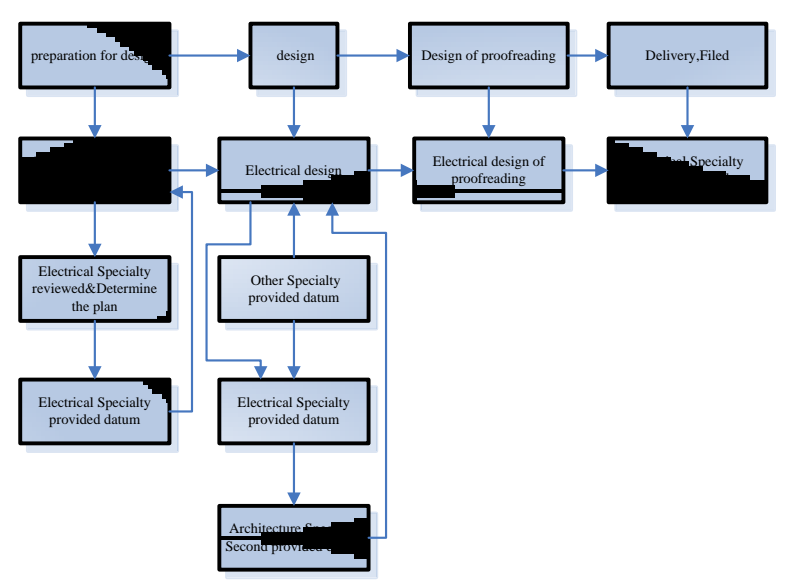

Figure 1. Traditional design process

From the perspective of the work process, including design, electrical design, school review, delivery and archiving. In the course of design and preparation, electrical major needs to confirm the information provided by the building professional, but also need to inform other professional design parameters and requirements of the professional, as a basis for design. From the perspective of data transmission, there is only a regular and node activity, which cannot be realized in the traditional way of designing information. The lack of correlation between the patterns, which is easy to cause the problem of different patterns of different patterns.

Through the above analysis, there are some shortcomings in the traditional electrical design method based on two-dimensional pattern, which is mainly reflected in the:

1)The lack of data association between two dimensional patterns cannot effectively ensure the consistency of the data, which will lead to the expression of the two-dimensional pattern of flat, vertical and crosssectional expression.

2) Two dimensional pattern cannot establish a direct data association between the professional and the various professional.

\section{B. Electrical design process based on BIM Technology}

Based on BIM technology, the work flow and data transfer can be changed obviously, and the design quality is improved obviously. From the perspective of the work process, the work flow based on BIM technology will be divided into six parts, including the design, electrical design, comprehensive coordination, the generation and adjustment of two-dimensional view, design school review, delivery and archiving, as shown in Figure 2. Compared with the traditional work flow, the main change is the following:

1) Electrical professional and professional coordination will run through the whole design process. Real time coordination can be realized in the process of electrical design, which can avoid or resolve the conflict of the design.

2) The process of generating and adjusting the $2 \mathrm{D}$ view is increased. After the creation of electrical design model, the traditional design and mapping process is transformed into a two-dimensional view process, which is not in conformity with the requirements of the design depth of the current implementation.

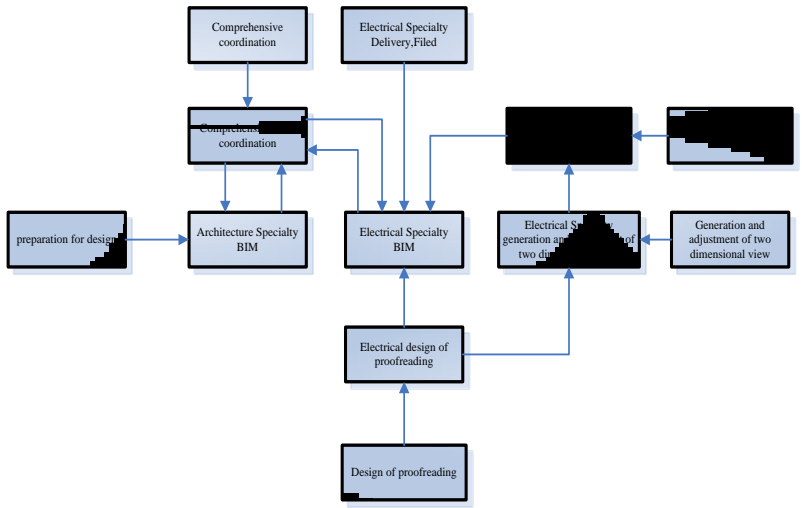

Figure 2. Design process based on BIM Technology

From the perspective of data transmission, the realization of the electrical and other professional and other professional data transfer and exchange. BIM model and 2D drawings will be delivered to the construction phase, to achieve data sharing. From the perspective of the work results, the model is consistent with the corresponding pattern generated, reducing the phenomenon of error, leakage, touch and lack, etc., to provide more accurate design patterns for the construction drawing stage. Through the above analysis, it is concluded that the construction drawing design process based on BIM technology has the following advantages:

1) Based on the BIM technology, the design method can express the spatial relationship of the professional and comprehensive, and can realize the coordination between the professional and professional.

2) In the aspect of design efficiency, because of the increase of the two dimensional view generation and adjustment link, the electrical professional workload has increased, but in the whole design process, reduce the coordination between professional and professional work, reduce the impact of design changes on the electrical professional, which will greatly improve the work efficiency, so the entire project cycle will be shortened.

3) It provides the technical means for the design optimization. BIM model created by the model contains a wealth of information, such as geometry and parameters, the information can be used for electrical power analysis, lighting analysis, etc., can also be used for load calculation, lighting calculation and lightning protection, etc..

\section{CONCLUSIONS}

With the continuous development of BIM technology in the field of engineering construction, the application of BIM technology in building electrical field has become a trend, and the application of BIM technology in the construction of electrical field has gradually received extensive attention of electrical designers. The characteristic of BIM technology is to make the design fine, visualization, and enhance the cooperation ability between professional and professional, reduce the occurrence of design conflict and other issues, and the pipeline comprehensive collision detection is a bright spot in the application of BIM technology. There are still some problems in the design and application of BIM in the actual project. First of all, the BIM software has not yet formed a unified standard to meet the design standards, the localization level still needs to be improved. Secondly, the 
content of the library is not perfect. The design personnel should be added according to the actual needs. Finally, the compatibility of BIM data and other analysis software is still to be optimized.

Today, BIM is extremely rich in electrical products, but the lack of information on the building model is just a shell without a soul. The establishment and the renewal of the electrical product information database is a huge project. The application potential of building electrical design based on BIM technology will bring huge impact to the traditional electrical design work.

\section{REFERENCES}

[1] Q.Z.Yang , Design knowledge modeling and software implementation for building code compliance checking[M]. Building and Environment,2004 (39),pp.689 698.

[2] Wang Xin, Huang Kuan, Gao Zhijun. The Primary Users' Signals Recognition Algorithm in Cognitive Radio Networks via KPCA and Random Forest[J].ICIC Express Letters,2015, 9(4):1083-1088.

[3] Thomas W. Hartmann, P.E.BIM-BAM-BOOM! More Bang for your BIM buck[J].Structures Congress, 2010,pp.1672-1675.

[4] $\mathrm{Na} \mathrm{Lu}$, Thomas Korman. Implementation of Building Information Modeling (BIM) in Modular Construction: Benefits and Challenges[J]. Construction Research Congress, 2010, pp. 11361145 .
[5] Dossick, C. and G. Neff, Organizational Divisions in BIM-Enabled Commercial Construction[J].Journal of Construction Engineering and Management, 2010. 136(4): pp. 459-467.

[6] Seo, J.-H.L., Baek-Rae Kim, Ju-Hyung Kim, Jae-Jun, Collaborative Process to Facilitate BIM-based Clash Detection Tasks for Enhancing Constructability[J]. Journal of the Korea Institute of Building Construction, 2012. 12(3): pp. 299-314.

[7] Hanna, A., F. Boodai, and M. El Asmar, The State of Practice of Building Information Modeling (BIM) in the Mechanical and Electrical Construction Industries[J]. Journal of Construction Engineering and Management, 2013: p. 10.1061/(ASCE)CO.19437862.0000747

[8] Hartmann, T., J. Gao, and M. Fischer, Areas of application for 3D and $4 \mathrm{D}$ models on construction projects[J]. Journal of construction Engineering and Management, 2008. 134(10): pp.776-785.

[9] Azhar, S., Building information modeling (BIM): Trends, benefits, risks, and challenges for the AEC industry[J]. Leadership and Management in Engineering, 2011. 11(3): p. 241-252.

[10] Wang Xin,Guo Lili,Ma Lina. Cooperative Spectrum Sensing Algorithm Based on Second User Selection and Random Forest Classification[J].ICIC Express Letters, Part B: Applications,2015, 6(3): 845-850.

[11] Teicholz, P., R. Sacks, and K. Liston, BIM handbook: a guide to building information modeling for owners, managers, designers, engineers, and contractors[M]. Wiley. 2011. 